\title{
Structure, adaptability and security of an architectural object
}

\author{
Yuliya Yankovskaya ${ }^{1 *}$, Tamara Datciuk $^{1}$, Lidiia Kondratieva $^{1}$, and Rashid Mangushev ${ }^{1}$ \\ ${ }^{1}$ Saint Petersburg State University of Architecture and Civil Engineering, 2nd Krasnoarmeyskaya \\ Street, 4, Saint Petersburg, 190005, Russia
}

\begin{abstract}
The paper is devoted to the improvement of the modern methodological apparatus for describing and modeling the structure of architectural objects, which is focused on current trends in the design of buildings and structures with a certain degree of variability and adaptability to rapidly changing modern requirements of potential and real users and external environmental conditions (natural, man-made). In addition, the complexity and variability of the structure of architectural objects directly affect the increase in their operational characteristics, the improvement of security systems and the hierarchy of structures of spaces of different access levels. Another aspect of this problem is the creation of a scientific basis for the formation of a more flexible regulatory framework in architecture.
\end{abstract}

\section{Introduction}

The urgency of considering this problem is associated with the need to develop the methodological apparatus of the theory of architecture, focused on the formation of an architectural environment adequate to modern society's needs, which contributes to the realization of the diverse requirements of real and potential consumers.

Modern sociocultural conditions of society and the development of new technologies that change all spheres of human activity cause a rapid change in needs that determine the use of various architectural objects by a person (buildings and structures, their subject content and the architectural environment as a whole). As a result, a multiplicity and variability of their use occur.

It is necessary to take into account that before, in the conditions of a relatively stable socio-economic structure, the consumer, as a rule, was oriented towards the long-term use of the architectural object within strictly defined functional frameworks. And in modern conditions, buildings and structures move more quickly from one consumer to another, often completely changing its functional content and appearance. Each new owner has his own system of representations and value priorities regarding the structure used, namely the functional structure, technological security, media, brand and other quality characteristics of the architectural object. There is a need for the formation of modern approaches to the design of architectural and environmental objects with a morphological structure that

\footnotetext{
* Corresponding author: jul3203226@gmail.com
} 
provides the ability to transform, which is determined by the constant change in the needs of users, while issues related to ensuring the safe use of objects are significantly updated.

\subsection{Problem}

The appeal to this methodological problem - the improvement of ideas about an architectural object, is caused by a number of contradictions that exist today in architectural theory and practice:

- the first block of contradictions is associated with the acceleration of the pace of life of a modern person, entailing constant changes in all spheres of his life, and the presence of inappropriate methods of traditional stable organization of architectural objects and the environment;

- the second block of contradictions is associated with the first one. It is revealed at the level of organization of design processes that should focus on the optimal consideration of the diverse and rapidly changing needs of potential owners and consumers of architectural objects;

- the third block of contradictions is associated with insufficient understanding of the humanistic role of architecture in the modern world, as the basis for the self-realization of not only the architect, but also the consumer.

\subsection{Scientific context}

This work is in line with the methodological positions of the Russian phenomenological trend in architectural studies, the foundation of which was laid by A.G. Gabrichevsky back in the 1920s [1]. In European architectural studies, this direction was developed in the research of Cr. Norberg-Schulz [7-9], Cr. Day, J. Mutanyola-Thornberg. It was based on the humanitarian works of M. Merlo-Ponty [5], M. Heidegger, P. Ricoeur [6].

The phenomenological discourse that defines the author's position also determined the basic provisions of the work:

- embodiment of spatial experience as the original foundation of architecture;

- consideration of the architectural object as experienced by a person in the process of interaction, which in turn entails a review of traditional views on the architectural typology;

- importance of the formation of a polysubjective position in architecture as an orientation to intersubjective interactions in the architectural process.

The interpretation of the morphological characteristics of the architectural form is based on the classic works of $\mathrm{H}$. Wölfflin [2] and A. Hildebrand [3], A. Brinkman, W. Groppius [11], Z. Gidion, I. Araujo, R. Arnheim, etc. [4]. The morphological structure of the architectural object is built from the perspective of the "barrier method" originating in the opposition of "emptiness-mass" in the works of R. Arnheim, M. Ginzburg, B. Zevi and others, and was developed in more modern architectural publications and works of the middle of the XX century by L. Kahn, Cr. Norberg-Schulz [7, 9].

The position with respect to typological construction in architecture is in line with the search for an alternative to the traditional functional approach. The following scientists conducted their studies in this area: A. Rossi (typology based on stable geometric archetypes of the architecture language), L. and R. Kreir (typology based on the prototypes and structural archetypes of spaces) [10], L. Kahn (in his works, it is possible to distinguish typology based on the structure of connections) and others. From a methodological point of view, this interpretation of the typological approach develops the traditions of humanitarian typologies of M. Bakhtin, M. Weber, H. Becker.

Foreign publications on the modern "eco-tech" architecture of R. Saxon, C. Slessor [12], M. Wiggintin [14] and the design activities of architects N. Foster [13], N. Grimshaw, 
R. Rogers, R. Piano, T. Herzog, J. Nouvel and others influenced the formation of the adaptability concept.

\subsection{Hypothesis}

The consistent application of basic phenomenological principles in the work leads to the identification of a new subject area that reveals an architectural object as a part of being experienced by a person from the position of his basic needs, having a certain morphological structure, which is the result and a sufficient condition for human activity, acting as an intermediary in interaction with the environment. This, in turn, leads to the actualization and implementation of the needs of various subjects in the design process, and not only those adopted by the architect [15].

As part of the problem posed, the study set a goal - the formation and justification of methods for describing and modeling the morphological structure of architectural objects and the development on its basis of an adaptive architectural typological system that can be further used to develop modern approaches to designing and improving the regulatory framework in architecture.

\section{Materials and methods}

The author's worldview is determined by the phenomenological approach. Proceeding from this, the architectural object is considered from the perspective of its physically-spatial experience by a person in the process of interaction. The morphology of the object and the reflection of the value semantic component in it are put forward as basic representations. Structures were chosen as analytical tools, which implies the selection of a set of stable relations of the object, ensuring its identity and reproducibility under changing conditions, both external and internal.

Of great importance for this study is a modern modification of the typological approach focused on understanding and describing modern manifestations of form-formation and type-formation in architecture through building a construct that performs the function of substantiating, comparing, and highlighting the minimum of basic forms and their possible invariants. The author's development is an architectural typological method, on the basis of which a developing typological system is built, focused on the design of adaptive structures of architectural objects and determination of their consumer qualities.

Also, modern analytical methods and a modeling method are used in the paper.

The specifics of this study are determined by the following provisions:

- firstly, the formation and development of new methodological approaches in architecture should be focused on solving the problems of architecture practice in modern socio-economic conditions determined by the culture of consumption;

- secondly, the consideration of an architectural object as a part of being experienced by a person from the perspective of fulfilling his needs, which has a certain material and semantic structure, is a condition for a person's activity, performs an intermediary function in interaction with the environment. In the architectural object, various changeable needs of various subjects are actualized, and the potential adaptability of the object, together with the possibility of creating systems of restrictions, contributes to their optimal and safe implementation.

Turning to the main content of the study, we highlight the main structural elements of the presentation:

- transition from the traditional morphological description of architectural objects to the formation of a morphological structure in line with the phenomenological discourse; 
- substantiation of the developing typological system in architecture on the basis of the proposed morphological developments;

- improvement of the typological system in architecture through updating the adaptability and security of architectural objects.

\section{Results}

\subsection{Traditional morphological descriptions of architectural objects}

Morphological tools for describing the basic spatial characteristics of an object related to the needs of a person in creating a system of constraints and the need for orientation are based on compositional techniques, such as a description of the properties of forms and compositional means, the properties of spaces and methods of controlling human movement, the alternation of techniques for organizing spaces, etc. Morphological means associated with the basic sensory qualities of an object are described through various characteristics of the object that determine its typology (in its traditional sense), such as orientation, means of providing insolation and lighting, means of protection against overheating / overcooling / noise / wind / dust, and also - methods and means of gardening and watering, specifics of using materials, etc.

Morphological means of forming the socio-cultural characteristics of an object, endowing it with a certain social significance, are associated with recognition and semantic (interpretative) characteristics. Recognition of an object is based on the connection of the spatial characteristics of the object with a certain social process for which it is used and the fixation of this connection within the framework of the system of representations of a given society. Recognition, as a rule, is associated with the following indicators: the size of the building, identified by the number of storeys; the nature of dividing and detailing, determining the scale and purpose of the object; means of forming plasticity of volume and facade surfaces. Morphological tools that determine the possibility of secondary semantic interpretations of an object are based on the use of the historical and genetic, compositional and associative potential of the environment, as well as the potential of architectural forms (traditional architectural forms with stable meanings; new event forms; simple geometric forms with an infinite number of meanings).

Obviously, the traditional compositional and typological methods for describing the morphology of architectural objects need to be supplemented with a set of basic components that determine the interaction of a person with the subject and spatial environment. These components are the "barrier" that identifies and limits the space of action of a person/group and the "stimulus" that determines the nature and possibility of action in the allocated space.

\subsection{Morphological structure of an architectural object}

The approach to the formation of the morphological structure of an architectural object (and a system of its description) is based on the scientific developments of professor Yu.S. Yankovskaya. It is based on the basic position on the fundamental duality of the description of the morphology of an architectural object [1]: a spatial and physical description, including the position of the subject, and abstract geometric description, excluding the position of the subject from the description.

The spatial and physical description operates with two initial parameters - "barrier" and "stimulus". The form of such a description proceeds from the physical interaction of a person and an object, and is based on biological stereotypes. Biological stereotypes are 
forms of biological heredity that depend on the physicality of a person. Based on this, they determine the horizon and unity of spatial experience without rational and functional interpretations [15].

The abstract geometric description is the basis of compositional and typological representations, which are traditional for architectural morphology. This description form describes an object that exists regardless of the subject. The emergence of "ideal" (extrasubjective) realities and the development of the process of separating the "ideal" from the "real" is carried out through natural language, i.e. such descriptions are secondary to basic ones defined by biological stereotypes.

So, the morphological structure of an architectural object is described through a system of barriers and stimulus, which is determined by the introduction of a person with his physicality into a subject and spatial environment, where the physicality of a person determines the specifics of interaction with the object. The proposed approach to the formation of a morphological description proceeds from emphasizing the priorities of the needs of the subject.

The description of the morphological structure of an architectural object in this [15] interpretation is based on the identification of two levels - physically and culturally determined:

- the basic physically determined level describes the architectural object as a "barrier stimulus" system; material barrier - restricts a person's movement, allocates space for action and determines the degree of interaction/isolation with the environment; stimulus plays the role of a carrier of irritation that causes human action; it determines the advantage of certain actions/movements of a person in a separated/allocated space, the choice of priority impact;

- culturally determined level of descriptions is based on the correspondence of generalized morphological characteristics to the speech equivalent. Typical morphological characteristics and their stable combinations form the space-planning structure of the object, which is described through the orientation and planning and plastic structures. The orientation and planning structure includes the communication frame of the building and the functional filling elements (halls, cell rooms, etc.), and is described through the variables of the "stimulus". The plastic structure is a system of barriers with varying degrees of permeability/impermeability and proportionality to human. It fixes the orientation and planning structure in material elements and is described through the variables of the "barrier".

\subsection{Typological system}

On the basis of the system of description of the morphological structure of an architectural object disclosed in this paper, the concept of a developing architectural and typological system, proposed in the doctoral dissertation by Yu.S. Yankovskaya, is formed [15]. The starting point for building a typological system open to development is the priority of the consumer entity, which determines the value characteristics of the architectural object, which are manifested in the process of use and are fixed in the morphological characteristics of the object. Subject field - modern civilian facilities (buildings and their complexes, structures), built/designed in recent decades. The generalizing principle is openness to development and adaptability of the typological system. This principle determines the orientation of the typological system towards the search and creation of new typological structures of architectural objects. The tool for type substantiation is the "barrier - stimulus" system. The means of distinguishing types is the character of building a spatial planning structure having attributive (orientation and planning) and modus (plastic) characteristics. 
The basic types of objects are determined on the basis of identifying the specifics of constructing the orientation and planning structure, the means of comparison differentiation, structure, capacity of the communication frame and filling. Basic types have genetic, structural, typical relationships and allow implementing the variability of consumer decisions based on a basic planning solution; have the ability to offset and modify; cover the entire subject field. Invariants of the basic types are determined based on the attributive qualities of the plastic structure of the object. The criteria for distinguishing the invariants are the characteristics of the barrier - the plane of the fence, such as: the nature of permeability, structure, curvature of the surface of the barrier, and also its transformability (mobility, change in the degree of permeability, etc.).

Openness to the development of a typological system is also ensured, in addition to the specifics of its construction, by such a position as "adaptability", which determines the possibility and nature of the allowed modifications / changes in the space and planning structure of an architectural object, which in turn affects the consumer and operational characteristics of architectural facilities and their compliance with changing socio-cultural, economic, and environmental requirements. Openness to development and adaptability of the typological system are focused on the construction of new heuristic types and structures of architectural objects, the creation of opportunities for the realization of human needs that vary and change over time, the optimal alignment of the object's interactions with the external environment, providing comfortable and safe characteristics of the architectural space for humans.

In the framework of building a developing architectural and typological system, the concepts of adaptability and safety of an architectural object were put forward.

\subsection{Adaptability of an architectural object}

In the framework of building a developing architectural and typological system, the concept of adaptability of an architectural object was put forward, which includes the following provisions [15]:

- adaptability, which is revealed as a specific of organization of an architectural object, which determines the possibility and degree of change in the structure of an architectural object, while maintaining the stability of its consumer characteristics under the changing needs of users, as well as external and internal environmental impacts;

- potential variability of the structure of an architectural object, which is determined by: variability/stability of the planning structure, hierarchy / multilayer / mobility of the plastic structure, change in visual and tactile permeability of barriers;

- the use of systems with weak differentiation of the communicative frame and filling, as well as their invariants - embedded systems that give the best characteristics in terms of openness to possible changes.

The potential structural variability of an architectural object and its adaptation to the needs of the user is determined by the use of space and planning structures with poor differentiation of the frame and filling, with numerous embeddings, variable permeability and transformability of the barriers. It is ensured by the presence of a number of extensive multi-level spaces that permeate the entire volume of the building and allow achieving variability in the placement of communication systems. In an embedded system, the nature and number of embeddings, the capacity of the embedded filling elements, and the characteristics of the barriers change parametrically. The nature of the barriers is changing: from a system of multilayer barriers to a system of embedded spatial volumes; from full to partial tactile and visual permeability; from orthogonal to curvilinear (chaotic) layout grids; from artificial to "green / water" component as barriers. 


\subsection{Security and restriction systems}

Let's list the basic requirements for ensuring security and the formation of restriction systems in an architectural environment $[17,24]$ :

- determination of the zone of influence of the object and the allocation of its site includes: demarcation of the various access zones of the territory, removal of restricted access zones from the main movement routes, separation of transport and pedestrian traffic, differentiation of sites of various purposes;

- formation of access control near the site, the entrances to the object;

- competent organization of the system of barriers, both artificial and natural (including the use of green spaces and watering);

- prevention and suppression of vandalism by maintaining the facility, the adjacent territory and infrastructure in working condition;

- adequacy and discreetness of preventive measures.

Next, we will consider a more applied aspect of the morphological organization of an architectural object - a means of forming restriction systems in an architectural environment.

The first most traditional means of forming restriction systems is the installation of water barriers. It has a long history and is the most aesthetically attractive and effective. The installation of water barriers in most cases excludes the possibility of direct penetration into the territory of an object. The use of this tool can be supplemented by a compact closed spatial solution and the presence of courtyards equipped with modern means of monitoring the territory. The second traditional means is the formation of closed spaces with limited access and a video surveillance system. A specific area of development of the first two means is the formation of partially-closed residential formations opened to the water. Another traditional means is the formation of an open environment of an object in a fairly isolated large urban development.

The means of structural differentiation of spaces used in the formation of such architectural and town-planning formations, which due to their planning structure provide differentiation and hierarchy of access to residential, public, infrastructural and other components deserve particular attention and study.

\section{Discussion}

The methodological provisions presented in the paper have received a certain interpretation and testing in the educational process within the framework of design and research disciplines of the Faculty of Architecture of the St. Petersburg State University of Architecture and Civil Engineering in cooperation with engineering departments such as the Department of Architectural and Construction Structures, the Department of Building Physics and Chemistry, Department of Geotechnics, etc.

In addition, the applied development and methodological developments presented in the paper were continued in doctoral studies [24-26] carried out under the supervision of Yu.S. Yankovskaya in the last decade [16-23]:

- methodology of morphological analysis in the doctoral study of O.A. Ulchitskiy [16] "Features of architecture of the proto-cities of the ancient Urals (using the example of Arkaim)" (2006) and doctoral study of E.R. Polyantseva [17] "Architectural and planning means for ensuring the security of civil buildings" (2016);

- methodology for the morphological analysis of the appearance of a house and a model for the formation of the appearance of a house in adverse conditions of an industrial city in the doctoral study of M.Yu. Chikoty [18] "The appearance of a modern house in adverse conditions of an industrial city (using the example of Magnitogorsk)” (2007); 
- the use of typological developments in the development of space and planning models of multifunctional public buildings in doctoral dissertations of I.A. Bozhenko [19] "Architectural environment of multifunctional public buildings (using the example of Western and Russian architecture)" (2009); O.V. Tsaizer [20] "Architectural and spatial organization of transformable sports facilities" (2015), E.K. Ryabova [21] "Architectural formation of the educational environment of creative universities" (2012);

- a number of provisions related to typological developments were used in the doctoral studies of E.E. Baksheeva [22] "Architectural and recreational environment of closed water parks" (2011) and E.A. Golubeva [23] "Humanization of the architectural environment of parking in the city structure (using the example of Yekaterinburg)" (2007).

In the future, it is planned to develop certain aspects of the concept of "developing typological system" in the following areas:

- development of the concept of adaptability, as applied to individual typological groups of architectural objects;

- development of morphological and typological descriptions within the framework of the formation of security systems and restrictions in the modern design process;

- development of morphology in the area of subject-oriented and culturally determined form-forming searches in the building architecture.

Prospects for further practical use of the presented developments are seen in optimizing approaches to the design of architectural objects and in improving the regulatory framework in building architecture [24-29].

\section{Conclusions}

The paper summarizes and develops a number of developments aimed at improving the methodological apparatus of architectural typology, the development of humanistic subjectoriented approaches to the design of buildings and complexes and increasing their operational characteristics due to their adaptability. The presented paper:

- showed the transition from the traditional morphological description to the interpretation of the morphological structure of an architectural object, which is based on the spatialphysical and socio-cultural description of an object;

- considered the concept of a developing and adaptive typological system in architecture;

- emphasized the provision on the fundamental adaptability of a modern architectural object as reflecting the rapidly changing requirements of potential consumers and users to the architecture of buildings and structures and their operational characteristics;

- showed the areas of further improvement of the concept of a developing typological system in the area of ensuring adaptability, transformability, security of architectural objects and the formation of restriction systems.

\section{References}

1. A.G. Gabrichevsky, Morphology of art (AGRAF, Moscow, 2002)

2. H. Wölfflin, Interpretation of art (Dolphin, Moscow, 1922)

3. A. Hildebrand, The problem of form in the visual arts and collection of articles (Musaget, Moscow, 1914)

4. Grammaire de la Architecture (Dessan et Tolra, Paris, 2002)

5. M. Merlo-Ponty, Phenomenology of perception (Routledge \& Kegan Paul, Paris, 1962)

6. P. Ricouer, P 1985 Temps et recit (University of Chicago Press, Chicago, 1985)

7. Cr. Norberg-Schulz, Existence, Space and Architecture (Praeger, New York, 1971) 
8. Y. Yankovskaya, A. Merenkov, IOP Conference Series: Materials Science and Engineering, 262, 012134 (2017)

9. Y. Yankovskaya, Proceedings of the Latvia University of Agriculture Landscape Architecture and Art, A Ziemelniece (ed.), 2, 50-59, Latvia University of Agriculture, Jelgava (2013)

10. R. Krier, Architectural Design, 9, 10 (1980)

11. W. Groppius, Arhitectur, Frankfurt (1956)

12. C. Slessor, Sustainable Architecture and High Technology (Thames \& Hadson, London, 2001)

13. P. Asensio, A. Cuito, Foster and partners (TeNeues, Barselona, 2002)

14. M. Wiggintin, M 2003 Glass in architecture (Phaidon, New York, 2003)

15. Yu.S. Yankovskaya, Architectural object: image and morphology (MarchI, Moscow, 2006)

16. O.A. Ulchitskiy, Features of the architecture of the proto-cities of the ancient Urals (using the example of Arkaim) (Ural State Academy of Architecture and Arts, Yekaterinburg, 2006)

17. E.R. Polyantseva, Architectural and planning means for ensuring the security of civil buildings (SPbGASU, St. Petersburg, 2016)

18. M. Yu. Chikota, The appearance of a modern home in adverse conditions of an industrial city (using the example of Magnitogorsk (Ural State Academy of Architecture and Arts, Yekaterinburg, 2007)

19. I.A. Bozhenko, Architectural environment of multifunctional public buildings (using the example of Western and Russian architecture) (NNGASU, Nizhny Novgorod, 2009)

20. O.V. Tsaizer, Architectural and spatial organization of transformable sports facilities (SPbGASU, St. Petersburg, 2015)

21. E.K. Ryabova, Architectural formation of the educational environment of creative universities (Ural State Academy of Architecture and Arts, Yekaterinburg, 2012)

22. E.E. Baksheeva, Architectural and recreational environment of closed water parks (SPbGASU, St.Petersburg, 2011)

23. E.A. Golubeva, Humanization of the architectural environment of parking in the city structure (using the example of Yekaterinburg) (Ural State Academy of Architecture and Arts, Yekaterinburg, 2007)

24. Y. Yankovskaya, A. Merenkov, Proceedings of the Latvia University of Agriculture Landscape Architecture and Art, A. Ziemelniece (ed.), 2, 77-84, Latvia University of Agriculture, Jelgava (2013)

25. O.A. Ulchitskiy, E.K. Kazaneva, O.M. Veremey, et al., O M, Bulatova E K, ARPN Journal of Engineering and Applied Sciences, 11, 5 (2016)

26. E.K. Bulatova, O.A. Ul'chickij, Scientific Herald of the Voronezh State University of Architecture and Civil Engineering. Construction and Architecture, 1 (25), 92-104 (2015)

27. A. Vaytens, Y. Yankovskaya, MATEC Web of Conferences, 170, 02001 (2018)

28. Y. Yankovskaya, Y. Lobanov, V. Temnov, E3S Web of Conferences, 33, 01029 (2018)

29. R. Gambassi, Architecture and Engineering, 2, 1, 3-24 (2017) 